\title{
Numerical analysis of the cross rolling process of a hollow railway axle
}

\author{
Analiza numeryczna procesu walcowania poprzecznego \\ drążonej osi kolejowej
}

Presented is an innovative method of manufacturing hollow railway axle using three rolls. The novelty of the solution consists of the simultaneous forming of the hollow axle by three tools, which allows to quickly remove ovalisation of the cross-section of the workpiece. The correctness of the proposed solution was verified using numerical simulation. The influence of the rollers' rotational speed on the forming process was analysed. The shape progression of the formed hollow axle, the effective strain, temperature and damage function distributions are presented. It is also shown how the force and torque on the rollers change during the rolling process.

KEYWORDS: cross rolling, hollow railway axle, FEM

Przedstawiono innowacyjną metodę wytwarzania osi kolejowych z użyciem trzech walców. Nowość rozwiązania polega na jednoczesnym kształtowaniu drążonej osi przez trzy narzędzia, co pozwala na szybkie usunięcie owalizacji przekroju poprzecznego obrabianego elementu. Proponowane rozwiązanie sprawdzono w symulacji numerycznej. Przeanalizowano wpływ prędkości obrotowej walców na przebieg kształtowania. Przedstawiono geometrię ukształtowanej drążonej osi, rozkłady intensywności odkształcenia, temperatury oraz funkcji zniszczenia. Pokazano również, jak w trakcie kształtowania zmieniają się siła i moment obrotowy na walcach.

SŁOWA KLUCZOWE: walcowanie poprzeczne, drążona oś kolejowa, MES

\section{Wprowadzenie}

Osie kolejowe są wielkogabarytowymi wyrobami produkowanymi w seriach liczących tysiące sztuk $[1,2]$. Obecnie głównymi technologiami stosowanymi w wytwarzaniu tego typu elementów są kucie swobodne oraz kucie na kowarkach.

Aby zmniejszyć masę osi kolejowych, próbuje się zastępować osie pełne ich drążonymi odpowiednikami. Takie elementy można wytwarzać, łącząc procesy dziurowania w walcarce skośnej oraz kucia na kowarkach [3]. Inną analizowaną techniką wytwarzania drążonych osi kolejowych jest walcowanie poprzeczno-klinowe (WPK) dwoma walcami [4-6]. Symulacje numeryczne oraz próby walcowania w skali pokazały jednak, że w tej metodzie trudno jest skutecznie usunąc owalizację przekroju poprzecznego. Problem ten można wyeliminować, korzystając z trzech narzędzi kształtujących (walców). Jednakże - jak wykazano w pracy [7] - ze względu na długość walcowanej osi trzeba wówczas stosować specjalne walce zespolone, co komplikuje przebieg kształtowania.

Alternatywą wobec rozważanych procesów WPK może być walcowanie poprzeczne trzema walcami. Jest to odmiana opracowanej i badanej na Politechnice Lubelskiej techniki obciskania obrotowego [8-10]. Rozwiązanie to opisano na przykładzie kształtowania osi kolejowej typu BA302, wytwarzanej w standardzie europejskim (rys. 1).

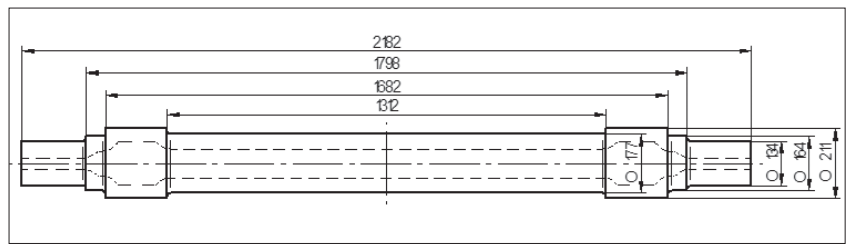

Fig. 1. Analysed railway axle BA302 (acc. to EN 13261)

Rys. 1. Oś kolejowa BA302 (wg EN 13261) będąca przedmiotem analizy

\section{Koncepcja kształtowania oraz zastosowany model numeryczny}

W analizie założono, że kształtowanie będzie realizowane ze wsadu rurowego, którego średnica zewnętrzna będzie równa średnicy maksymalnego stopnia osi powiększonej o wartość naddatku na obróbkę skrawaniem. Przyjęto zatem, że wsad ma średnicę zewnętrzną $\varnothing 217 \mathrm{~mm}$, długość $2070 \mathrm{~mm}$ i grubość ścianki $40 \mathrm{~mm}$.

Walcowanie jest realizowane trzema walcami, z których jeden przedstawiono na rys. 2. Walce są rozmieszczone na obwodzie wsadu co $120^{\circ}$, a ich osie znajdują się w odległości $520 \mathrm{~mm}$ od osi wsadu.

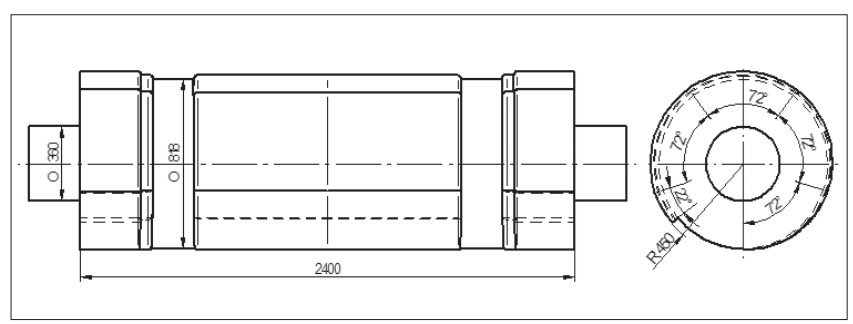

Fig. 2. Roller used in the process of cross rolling of a hollow railway axle

Rys. 2. Walec użyty w procesie walcowania poprzecznego drążonej osi kolejowej * Prof. dr hab. inż. Zbigniew Pater, z.pater@pollub.pl, https://orcid.org/0000-0001-5504-157X - Wydział Mechaniczny Politech-
-niki Lubelskiej, Lublin, Polska 
Kształtowanie wyrobu odbywa się przez oddziaływanie powierzchni roboczych walca. Ich odległość od osi przedmiotu obrabianego stopniowo się zwiększa na długości odpowiadającej obrotowi walca o kąt $216^{\circ}$. Ta część narzędzia jest nazywana strefą kształtowania i została podzielona na trzy równe części, różniące się intensywnością przyrostu promienia powierzchni roboczych. Jest on największy w pierwszej strefie (gdzie stanowi 50\% wartości przyrostu całkowitego), a najmniejszy w trzeciej strefie (20\% przyrostu). Taki sposób wykonania walców zapewnia bardziej równomierne obciążenie narzędzi.

Za strefą kształtowania znajduje się strefa kalibrowania, wykonana na łuku odpowiadającym obrotowi walca o kąt $72^{\circ}$. W tej strefie odległość powierzchni roboczych od osi walca jest stała, co skutkuje nadaniem kształtowanym stopniom wyrobu pożądanego kształtu cylindrycznego.

Za strefą kalibrowania znajduje się strefa wyjściowa, na łuku odpowiadającym obrotowi walców o kąt $22^{\circ}$. $\mathrm{W}$ tej strefie promień powierzchni roboczych stopniowo się zmniejsza (sumarycznie o wartość $5 \mathrm{~mm}$ ), dzięki czemu oś jest płynnie wyprowadzana ze strefy roboczej narzędzi. Na pozostałej części obwodu walców ich powierzchnie zostały znacząco obniżone, aby umożliwić wprowadzenie wsadu między narzędzia. Dodatkowo w jednym z walców wykonano wybranie (kieszeń), w które wpada odwalcowana oś.

Poprawność przyjętego rozwiązania sprawdzono numerycznie. Symulacje kształtowania wykonano w środowisku programu Forge NxT v. 2.1.

Na rys. 3 przedstawiono model procesu walcowania osi, w którym wykorzystano symetrię kształtowania. Przyjęto, że walce zachowują się jak ciała doskonale sztywne, podczas gdy przedmiot obrabiany zachowuje się jak ciało plastyczne, zgodnie z zależnością Spittela, która dla stali w gatunku 42CrMo4 jest wyrażona równaniem:

$$
\sigma_{\mathrm{p}}=1827,07 e^{-0,00289 T} \varepsilon^{-0,1123} e^{-0,4879 / \varepsilon} \dot{\varepsilon}^{0,14368}
$$

gdzie: $\sigma_{\mathrm{p}}$ - naprężenie uplastyczniające [MPa]; $T$ temperatura $\left[{ }^{\circ} \mathrm{C}\right] ; \varepsilon$ - intensywność odkształcenia; $\dot{\varepsilon}$ - prędkość odkształcenia $\left[\mathrm{s}^{-1}\right]$.

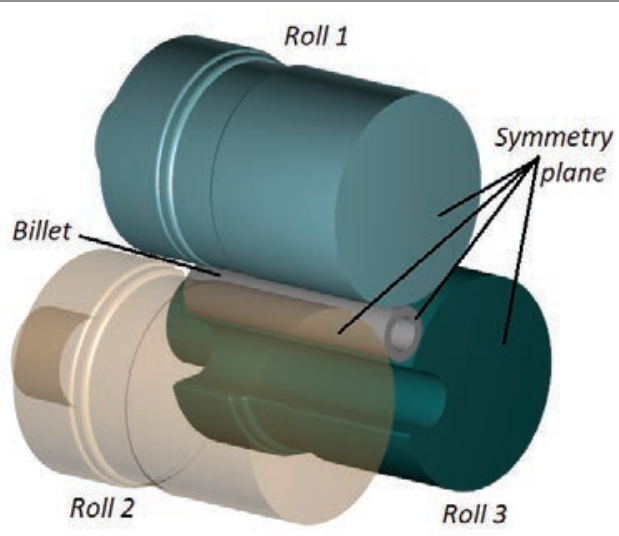

Fig. 3. Geometrical model of the 3-roll cross rolling process of a hollow railway axle

Rys. 3. Model geometryczny procesu walcowania poprzecznego trzema walcami drążonej osi kolejowej
Założono, że przed walcowaniem wsad był równomiernie nagrzany do temperatury $1200^{\circ} \mathrm{C}$, podczas gdy temperatura walców była stała w trakcie kształtowania i wynosiła $300^{\circ} \mathrm{C}$. Współczynnik wymiany ciepła między materiałem a narzędziami przyjęto równy $10000 \mathrm{~W} / \mathrm{m}^{2} \mathrm{~K}$. Tarcie modelowano na modelu tarcia stałego, dla którego przyjęto czynnik tarcia równy 0,8.

Rozpatrzono trzy przypadki kształtowania różniące się między sobą prędkością obrotową narzędzi, którą przyjęto za równą: 2,3 lub 4 obr/min.

\section{Wyniki}

Analiza numeryczna potwierdziła słuszność opracowanej koncepcji kształtowania drążonej osi kolejowej. Na rys. 4 przedstawiono przebieg procesu walcowania. Rozpoczyna się on od wsunięcia pomiędzy nieruchome walce wsadu rurowego. Następnie włączany jest napęd i wszystkie walce obracają się z jednakową prędkością w tę samą stronę - wykonują jeden obrót i kształtują oś. Otrzymany wyrób wpada w kieszeń jednego z walców i jest usuwany ze strefy roboczej walcarki. Po unieruchomieniu walców do strefy roboczej jest wprowadzany kolejny wsad i cykl kształtowania się powtarza.

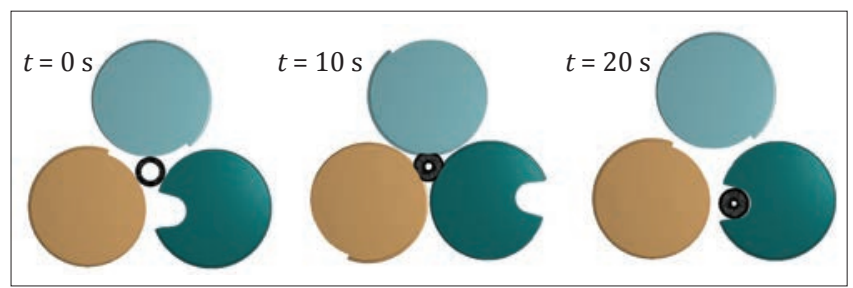

Fig. 4. Cross rolling process of a railway axle at $n_{\mathrm{R}}=3 \mathrm{rpm}$, depending on time $t$

Rys. 4. Przebieg procesu walcowania poprzecznego osi kolejowej przy $n_{\mathrm{R}}=3 \mathrm{obr} / \mathrm{min}, \mathrm{w}$ zależności od czasu $t$

Na rys. 5 pokazano progresję kształtu drążonej osi kolejowej w trakcie walcowania poprzecznego. Widać, że wszystkie stopnie osi są walcowane równocześnie. Materiał płynie głównie w kierunku promieniowym, a w przypadku stopnia skrajnego, o najmniejszej średnicy, także w kierunku osiowym, powodując wydłużenie elementu kształtowanego, który ostatecznie uzyskuje założoną długość. Wyniki symulacji pokazują, że proces walcowania przebiega stabilnie i na żadnym etapie wytwarzania osi nie występuje ograniczenie $\mathrm{w}$ postaci niekontrolowanego poślizgu.

$\mathrm{Na}$ rys. 6 przedstawiono rozkład intensywności odkształcenia w ukształtowanej osi. Rozkład ten jest typowy dla procesów walcowania poprzecznego. Odkształcenia są rozłożone $\mathrm{w}$ postaci pierścieniowych warstw i maksymalne wartości przyjmują w zewnętrznych warstwach, gdzie na materiał oddziaływały siły tarcia wywołujące płynięcie w kierunku obwodowym. Oczywiście zwiększenie redukcji średnicy materiału sprzyjało zwiększeniu intensywności odkształcenia.

Na podstawie rys. 6 można także określić zmianę grubości ścianki, która utrzymuje swoją początkową wartość $\left(g_{0}=40 \mathrm{~mm}\right)$ w obszarze stopnia o największej średnicy, niepodlegającego walcowaniu. W obszarze stopnia centralnego o największej długości grubość ścianki jest równomierna i wynosi ok. $52 \mathrm{~mm}$. 


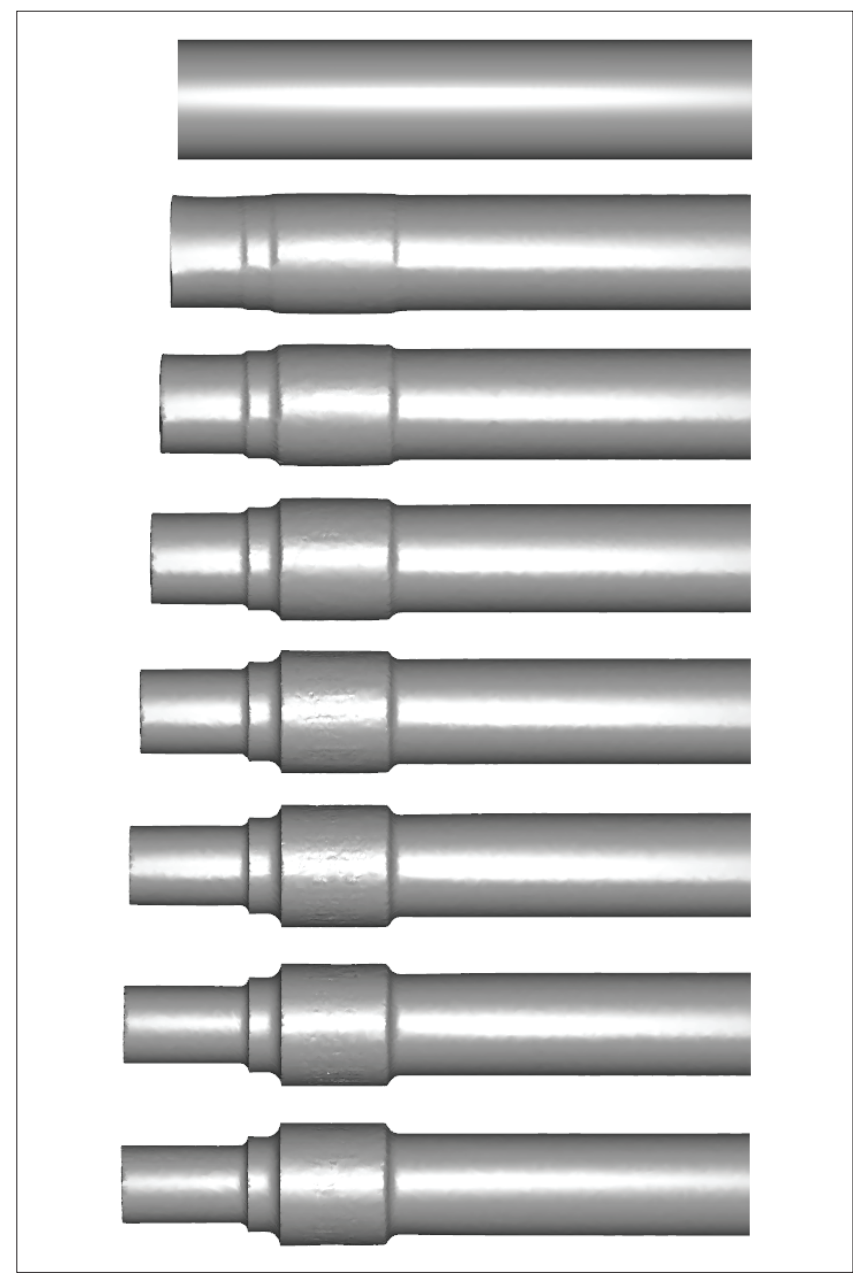

Fig. 5. Progression of the shape of railway axle rolled at $n_{\mathrm{R}}=3 \mathrm{rpm}$ determined for the time period $t=0 \div 17.5 \mathrm{~s}$ (with time increment of $2.5 \mathrm{~s}$ )

Rys. 5. Progresja kształtu osi kolejowej walcowanej przy $n_{R}=3 \mathrm{obr} / \mathrm{min}$ wyznaczona dla przedziału czasowego $t=0 \div 17,5 \mathrm{~s}$ (z krokiem co $2,5 \mathrm{~s}$ )
Pogrubieniu uległa także ścianka w stopniach bocznych i osiągnęła maksymalną wartość ok. $58 \mathrm{~mm}$ w miejscu przejścia ze stopnia pośredniego na stopień końcowy, którego ścianka z kolei ma grubość do $48 \mathrm{~mm}$. Pocienienie ścianki występuje jedynie na samym końcu osi. Jednakże ta część wyrobu zostanie odcięta w trakcie obróbki maszynowej, ponieważ ukształtowany wyrób jest o ok. $50 \mathrm{~mm}$ dłuższy od osi.

Do częstych ograniczeń występujących w procesie walcowania poprzecznego należy pękanie materiału. W przypadku elementów drążonych pęknięcia są lokalizowane na wewnętrznej powierzchni wyrobów [11]. Fakt ten znajduje potwierdzenie w rozkładzie funkcji zniszczenia, obliczonej zgodnie ze znormalizowanym kryterium Cockcrofta-Lathama (rys. 7). Największe wartości (dochodzące do 1) funkcja ta przyjmuje na powierzchni wewnętrznej stopnia centralnego. By powstało pęknięcie, wartość funkcji zniszczenia musi być większa od wartości granicznej, która dla stali w gatunku 42CrMo4 walcowanej przy temperaturze $1100^{\circ} \mathrm{C}$ wynosi 2,2 (wartość tę wyznaczono eksperymentalnie za pomocą autorskiej metody obciskania obrotowego w kanale [12]). Tym samym można jednoznacznie stwierdzić, że podczas walcowania poprzecznego osi kolejowej nie powinno dochodzić do niepożądanego pękania materiału.

Temperatura materiału w ukształtowanej osi kolejowej jest uzależniona od prędkości obrotowej walców $n_{\mathrm{R}}$, która z kolei przekłada się na czas kształtowania. Z danych zamieszczonych na rys. 8 wynika, że w przypadku walcowania z prędkością $n_{\mathrm{R}}=4 \mathrm{obr} / \mathrm{min}$ temperatura na powierzchni zewnętrznej osi przekracza $1000^{\circ} \mathrm{C}$, natomiast przy najmniejszej prędkości $n_{\mathrm{R}}=2 \mathrm{obr} / \mathrm{min}$ temperatura materiału $\mathrm{w}$ warstwach zewnętrznych jest o ok. $100^{\circ} \mathrm{C}$ niższa. Oddaleniu się

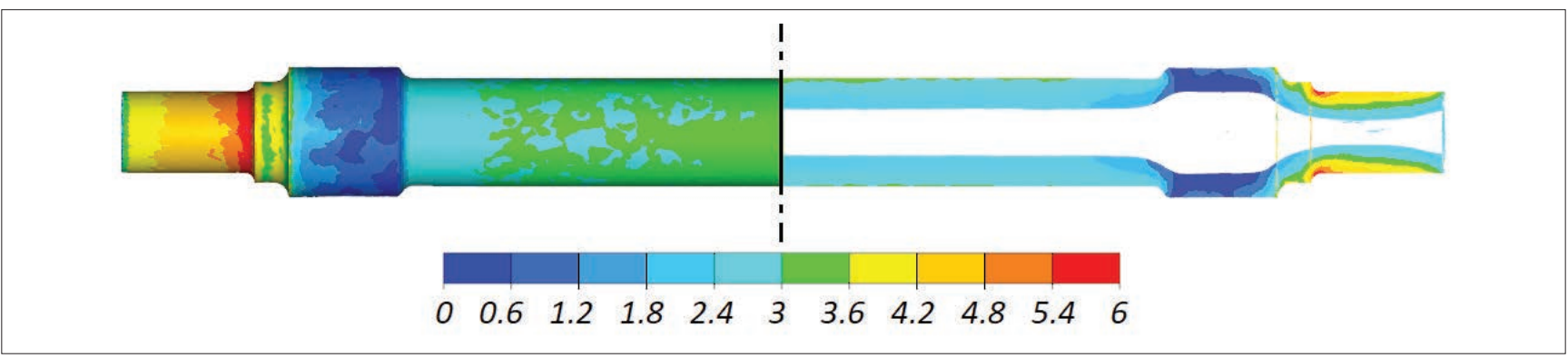

Fig. 6. Effective strain distribution for cross rolled hollow railway axle at $n_{\mathrm{R}}=3 \mathrm{rpm}$

Rys. 6. Rozkład intensywności odkształcenia dla drążonej osi kolejowej walcowanej poprzecznie przy $n_{\mathrm{R}}=3 \mathrm{obr} / \mathrm{min}$

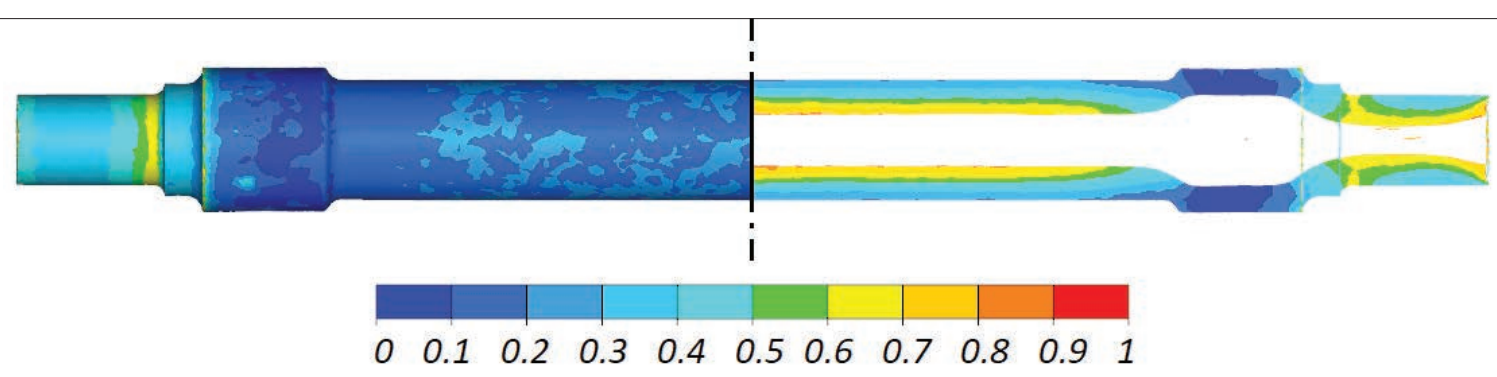

Fig. 7. Distribution of the damage function (calculated according to the normalized Cockcroft-Latham criterion) for a cross rolled hollow railway axle at $n_{\mathrm{R}}=3 \mathrm{rpm}$

Rys. 7. Rozkład funkcji zniszczenia (obliczanej zgodnie ze znormalizowanym kryterium Cockcrofta-Lathama) dla drążonej osi kolejowej walcowanej poprzecznie przy $n_{R}=3 \mathrm{obr} / \mathrm{min}$ 


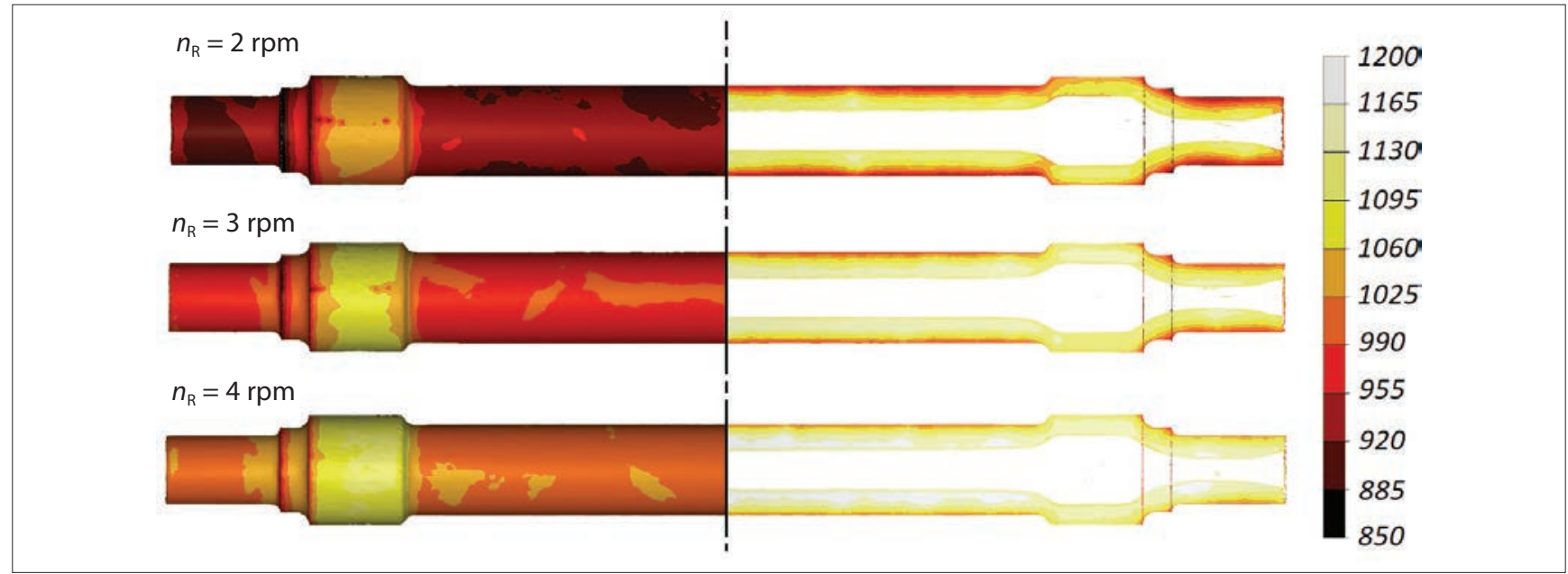

Fig. 8. Temperature distributions $\left[\right.$ at ${ }^{\circ} \mathrm{C}$ ] in hollow railway axles formed at different rotational speed of rolls $n_{\mathrm{R}}$

Rys. 8. Rozkłady temperatury $\left[\mathrm{w}^{\circ} \mathrm{C}\right] \mathrm{w}$ drążonych osiach kolejowych kształtowanych przy różnej prędkości obrotowej walców $n_{\mathrm{f}}$
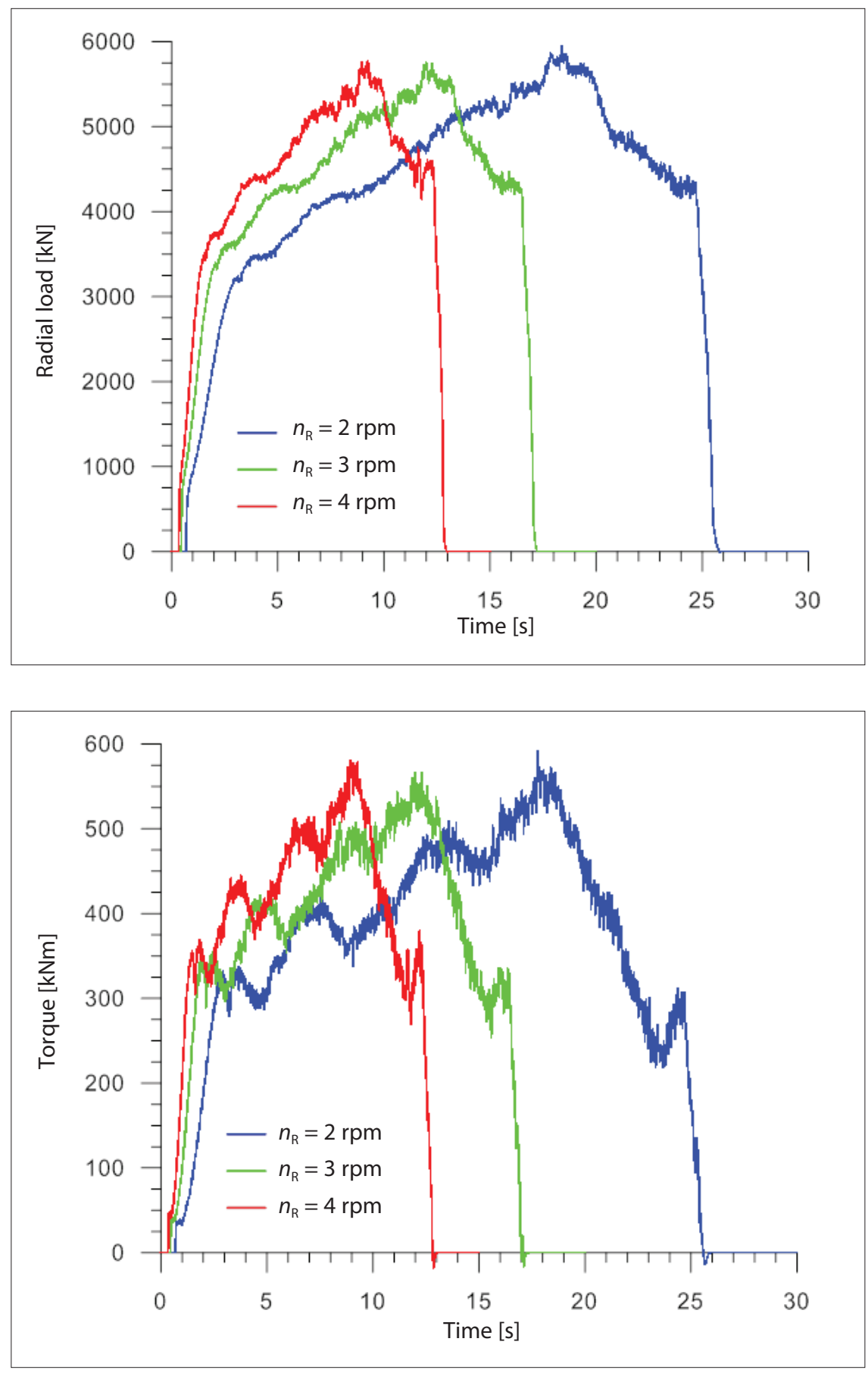

Fig. 9. Radial load on the roll during rolling process of the hollow railway axle depending on the rotational speed of rolls $n_{R}$

Rys. 9. Siła promieniowa na walcu w procesie walcowania drążonej osi kolejowej w zależności od prędkości obrotowej walców $n_{R}$

Fig. 10. Roll torque during rolling process of the hollow railway axle depending on the rotational speed of rolls $n_{R}$

Rys. 10. Moment obrotowy na walcu w procesie walcowania drążonej osi kolejowej w zależności od prędkości obrotowej walców $n_{R}$ 
od powierzchni zewnętrznej towarzyszy wzrost temperatury materiału, która na powierzchni wewnętrznej osi jest o ok. $150^{\circ} \mathrm{C}$ wyższa niż na jej powierzchni zewnętrznej. Taki rozkład temperatury jest efektem z jednej strony odprowadzania ciepła do znacznie zimniejszych narzędzi, a z drugiej strony - generowania dużych ilości ciepła w wyniku zamiany pracy odkształcenia plastycznego i pracy tarcia. Ostatecznie trzeba zaznaczyć, że we wszystkich trzech rozważanych przypadkach wartość temperatury materiału mieściła się w zakresie właściwym dla obróbki plastycznej na gorąco.

Na rys. 9 przedstawiono rozkłady siły promieniowej działającej na walec w procesie walcowania poprzecznego drążonej osi kolejowej w zależności od zastosowanej prędkości obrotowej $n_{\mathrm{R}}$. Rozkłady siły we wszystkich rozważanych przypadkach miały podobny charakter. Siła rosła w strefie kształtowania, a następnie zmniejszała się podczas kalibrowania. Największą wartość siły rozporowej (5949,6 kN) odnotowano w przypadku walcowania z prędkością $2 \mathrm{obr} / \mathrm{min}$. W pozostałych dwóch przypadkach wartość maksymalna siły była nieznacznie niższa (o ok. 3\%). Można zatem stwierdzić, że zmiana prędkości obrotowej walców w rozważanym zakresie nie ma wpływu na zastosowaną konstrukcję korpusu walcarki.

Rozkłady momentów obrotowych na walcu - pokazane na rys. 10 - mają podobny charakter jak rozkłady sił. Wartości średnie momentów dla prędkości obrotowych 2, 3 i 4 obr/min wynoszą odpowiednio: 309,1 kNm, 316,7 kNm oraz 326,5 kNm. Po uwzględnieniu czasu trwania cyklu walcowania wyznaczono energię potrzebną do ukształtowania osi, która była równa: 1941,4kJ, 1989,2kJ oraz 2050,5kJ, odpowiednio dla $n_{\mathrm{R}}=2,3 \mathrm{i} 4 \mathrm{obr} / \mathrm{min}$. Z kolei na podstawie wartości maksymalnych momentu obrotowego można określić, że minimalna moc silnika (potrzebna do napędu pojedynczego walca) w zależności od prędkości obrotowej uszeregowanej od najmniejszej do największej wartości wynosi odpowiednio: 123,8 kW $177,8 \mathrm{~kW}$ oraz $243,1 \mathrm{~kW}$.

\section{Wnioski}

$\mathrm{Na}$ podstawie analizy numerycznej sformułowano następujące wnioski końcowe:

- Za pomocą opracowanej metody walcowania poprzecznego trzema walcami można skutecznie kształtować drążone osie kolejowe.

- Osie kolejowe wytworzone metoda walcowania poprzecznego powinny być wolne od wad w postaci pęknięć wzdłużnych występujących na wewnętrznej powierzchni ścianki.

- W wyniku walcowania grubość ścianki wszystkich kształtowanych stopni osi ulega zwiększeniu.

- Pomimo stosunkowo długiego czasu kształtowania temperatura przedmiotu obrabianego utrzymuje się w zakresie właściwym dla obróbki plastycznej na gorąco; temperatura ta jest większa w przypadku zastosowania większych prędkości obrotowych walców.
- Realizacja proponowanej metody wytwarzania osi kolejowych wymaga zastosowania walcarki trójwalcowej o odległości między osiami walców a osią przedmiotu obrabianego równej $520 \mathrm{~mm}$. Maszyna powinna mieć korpus zdolny do przenoszenia obciążeń na poziomie $6 \mathrm{MN}$.

- Ze względów energetycznych za najbardziej korzystne należy uznać walcowanie drążonej osi kolejowej z prędkością obrotową $n_{\mathrm{R}}=2 \mathrm{obr} / \mathrm{min}$; minimalną moc walcarki zabezpieczającej kształtowanie drążonych osi kolejowych (dla tego przypadku kształtowania) szacuje się na $3 \times 125 \mathrm{~kW}$.

\section{LITERATURA}

[1] Shu X., Wei X., Li C., Hu Z. "The influence rules of stress about technical parameters on synchronous rolling railway axis with multi-wedge cross-wedge rolling". Appl. Mech. Mater. 37-38 (2010): 1482-1488, https://doi.org/ 10.4028/www.scientific.net/AMM.37-38.1482.

[2] Xu C., Shu X. "Influence of process parameters on the forming mechanics parameters of the three-roll skew rolling forming of the railway hollow shaft with 1:5". Metalurgija. 57, 3 (2018): 153-156.

[3] Romanenko V.P., Stepanov P.P., Kriskovich S.M. "Production of hollow railroad axles by screw piercing and radial forging". Metallurgist. 61, 9-10 (2018): 873-877, https:// doi.org/10.1007/s11015-018-0579-0.

[4] Hu B., Shu X., Yu P., Peng W. "The strain analysis at the broadening stage of the hollow railway axle by multiwedge cross wedge rolling". Appl. Mech. Mater. 444-495 (2014): 457-460, https://doi.org/10.4028/www.scientific.net/AMM.494-495.457.

[5] Peng W., Zheng S., Chiu Y., Shu X., Zhan L. "Multi-wedge cross wedge rolling process of $42 \mathrm{CrMo} 4$ large and long hollow shaft". Rare Metal Mat. Eng. 45, 4 (2016): 836-842, https://doi.org/10.1016/S1875-5372(16)30084-4.

[6] Zheng S., Shu X., Han S., Yu P. "Mechanism and force-energy parameters of a hollow shaft's multi-wedge synchrostep cross-wedge rolling". J. Mech. Sci. Technol. 33, 5 (2019): 1-10, https://doi.org/10.1007/s12206-019-0411-1.

[7] Pater Z., Lis K., Walczuk-Gągała P. "Numerical analysis of the cross-wedge of hollow rail axle". Advances in Science and Technology Research Journal. 14, 1 (2020): 145-153, https://doi.org/10.12913/22998624/115513.

[8] Pater Z., Gontarz A., Tomczak J., Bulzak T. "Producing hollow drive shafts by rotary compression". Arch. Civ. Mech. Eng. 15, 4 (2015): 917-924, https://doi.org/10.1016/ j.acme.2014.10.002.

[9] Tomczak J., Pater Z., Bulzak T. "Effect of technological parameters on the rotary compression process". Eksploat. Niezawodn. 15, 3 (2013): 279-283.

[10] Tomczak J., Pater Z., Bulzak T. "The influence of hollow billet thickness in rotary compression". Int J Adv Manuf Technol. 82 (2016): 1281-1291, https://doi.org/10.1007/ s00170-015-7437-z.

[11] Tomczak J. „Studium procesów obciskania obrotowego odkuwek drążonych". Lublin: Wyd. Politechniki Lubelskiej, 2016.

[12] Pater Z., Tomczak J., Bulzak T. "Rotary compression as a new calibration test for prediction of a critical damage value". Journal of Materials Research and Technology. 9, 3 (2020): 5487-5498, https://doi.org/10.1016/ j.jmrt.2020.03.074. 